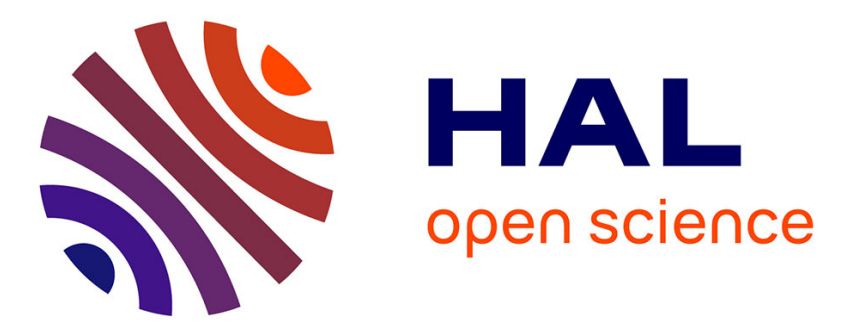

\title{
What month is it? The process of temporal orientation on a unit of the year scale
} Marie-Françoise Valax, Elyeth Tremblay, Françoise Sarocchi

\section{To cite this version:}

Marie-Françoise Valax, Elyeth Tremblay, Françoise Sarocchi. What month is it? The process of temporal orientation on a unit of the year scale. 2020. hal-02463216

\section{HAL Id: hal-02463216 https://hal.science/hal-02463216}

Preprint submitted on 31 Jan 2020

HAL is a multi-disciplinary open access archive for the deposit and dissemination of scientific research documents, whether they are published or not. The documents may come from teaching and research institutions in France or abroad, or from public or private research centers.
L'archive ouverte pluridisciplinaire HAL, est destinée au dépôt et à la diffusion de documents scientifiques de niveau recherche, publiés ou non, émanant des établissements d'enseignement et de recherche français ou étrangers, des laboratoires publics ou privés. 


\title{
What month is it? The process of temporal orientation on a unit of the year scale
}

\author{
M. F. Valax, E. Tremblay, F. Sarocchi \\ Laboratoire Travail \& Cognition, Maison de la recherche, \\ 5 Allées Antonio Machado, 31058 Toulouse Cedex, France \\ Contact : marie-francoise.valax@univ-jfc.fr
}

\section{Référence :}

Valax, M.F., Tremblay, E, Sarocchi, F. (1996). What month it is ? The process of temporal orientation on a unit of the year scale, Acta Psychologica,94, 1996, 309-317.

\begin{abstract}
The process of temporal orientation was studied in 977 subjects. They had to respond to one of the following questions : "What is (was, will be) the current (previous, next) month?", and to explain "how" they had come to answer as they did. In the majority of cases, temporal landmarks justifying the responses referred to the present, whatever the context of the question. The use of Future Landmarks increased from the beginning to the end of the month, and from the Previous Month question to the Next Month question. Response times varied with the type of temporal landmarks, and with the question context. On average, users of a Future Landmark responded faster. Results are discussed in relation to results of other studies using a "days of the week" scale. The different use of past, current and future landmarks supports a hypothesis that response identification depends on the functional importance of the landmarks underlying a spreading activation process.
\end{abstract}

\section{Author Note}

We gratefully acknowledge the assistance of Nadia Bourecrouche et Nathalie Hollevoët in the data collection 
What month is it? / M.F. Valax et al. 


\section{Introduction}

To coordinate their actions in line with the dynamics of their environment, individuals have to find their bearings in time. They must be able "to determine the current time and the relative times of other events with respect to some temporal framework" (Friedman, 1990, p.68). The few studies addressing this theme (Koriat and Fischhoff, 1974 ; Koriat, Fischhoff and Razel, 1976 ; Shanon, 1979; Friedman, 1990) fit in with a functional perspective on memory for time (Friedman, 1993). With regard to the "week" time scale, they show that temporal orientation is based on constructing a location in time.

Several studies have shown that days of the week are easier to identify at the weekend and around the weekend than on weekdays (e.g., Koriat et al.,1976 ; Shanon, 1979). These findings are compatible with the ones obtained in a study on the organization of memory for the time of events, in which subjects had to remember on what day of the week an interview was held 7 to 75 days prior to the test (Huttenlocher, Hedges and Prohaska, 1992). The authors note that errors in remembering a day of the week tend to be displaced towards the middle of the week, and that errors are infrequent for the two days of the weekend. The temporal representation of days of the week thus appears to be hierarchically organized. At the first level representations consist of a "weekday" unit and two distinct units corresponding to the two days of the weekend. For the "weekday" unit a second level represents the individual days. Within this framework, problems regarding temporal orientation for days of the week mainly will occur for weekdays. Weekend days, each having a specific representation, can be matched directly.

However, some findings cannot be explained with such a hierarchical matching process. When subjects fail to identify a weekday, they tend to give a response that is close to the correct one. In most cases, this is the previous day (Koriat et al, 1974). If errors were due to a comparison between the temporal unit of "weekdays" and day content, the responses should be spread evenly over the weekdays. The results, however, seem to indicate an error in the updating of a previous orientation. 
Such updating may depend on a spreading activation process among the units forming a network (e.g., Anderson, 1983 ; Rumelhart, Hinton and Williams, 1986 ; Shanon, 1979). Activation may depend on both external stimulation, and internal stimulation, i.e. activations spreading from neighboring cognitive or temporal units to the unit under consideration.

The main argument in favor of such a process hinges on the necessity of (almost) continuous temporal orientation. In order to adapt to the dynamics of his environment, a constant orientation of an individual is necessary. Although this may not be accurate, he/she must have an idea of "place in time". In this perspective, elapsing time is thought to be an essential factor in identifying a particular location in time. In a study investigating judgements about yesterday, today and tomorrow, Shanon (1979) found, for instance, that the accessibility of the past decreases as the accessibility of the future increases.

A number of different sources of information are likely to take part in a dynamic and constantly evolving representation of the location in time. Examples are actions and events in progress, short-term and long-term anticipations of actions and events (Valax and Cellier, 1992 ; Boudes and Tremblay, 1994), and temporally located recollections (e.g., Friedman, 1993 ; Huttenlocher et al., 1992 ; Lieury, Aiello, Lepreux and Mellet, 1980). Moreover, some studies dealing with everyday work situations (e.g. Leplat, 1985; WeillFassina et al., 1993) lend support to the role of intentional and contextualized representations of location in time.

The above-mentioned studies do not really enable a choice to be made between the two processess. One way of solving the problem would be to analyze the evolution of time identification for a single unit of time. Koriat et al. (1974) found that subjects having already mentioned today give a faster response than those who have not. In terms of a matching process, it could be assumed that the result of the identification of a particular "day" unit is stored in memory. In this case, at the beginning of the time unit studied (i.e., when it has to be identified for the first time), errors should be numerous and response times long, subsequently (i.e., when it has been identified before) decreasing and 
stabilizing until the end of the time unit. In terms of a spreading activation process, variations in performance would depend less on the moment within the time unit, and more on the state of the subject's representation when he is asked. In this case, time of testing would have an effect on performance only through factors determining the activation state of the target representation. We will test these processes by studying answers and response times to questions regarding the months of the year. A month is a unit of time that is long enough to justify several successive orientations. A month also has methodological advantages over a day. Firstly, physiological rhythms that may cause performance to vary during the day should not interfere over a month. Secondly, since human subjects generally sleep at night, they are inaccessible at such times. Conversely, over a month, data collection can be spread out homogeneously throughout the whole unit of time under study.

\section{Method}

\subsection{Subjects}

Nine hundred and seventy seven adults participated in the study. They were recruited by two experimenters in public places (public gardens, exits of cultural and social events, campus grounds, etc.), the even days of February and March 1994. Passers-by were requested to participate in a short experiment, then asked after agreement. The experimenters had approximately to balance the factors of age (20 to 60) and employment/unemployment. An attempt was made to obtain 36 subjects (18 males and 18 females) each of the 29 experimental day. This was possible each day, except on the February 8th, March 2nd and 4th (18 Ss each), on the March 6th (24 Ss) and 20th (35 Ss).

\subsection{Procedure}

Each subject was asked two questions, a neutral question at first ("Could you quote the name of a country whose first letter is A ?"), then one of the following experimental questions : "What was the last month ?" (PsM question), "What is the current month ?" (CM question), "What will be the next month ?" (FtM question). Each of these 
experimental questions was investigated three times per day, in the morning (7-9 a.m.), at midday (12 noon-2 p.m.) and in the evening (9-11 p.m.). The response time was measured using a stop-watch, triggered at the end of the question and stopped at the beginning of the (correct or incorrect) response.

After producing a response, the subject was freely asked to describe how he/she had determined the identity of the month in question. These descriptions were noted, and classified afterwards according to their temporal features as explained below.

\section{Results}

The effects of three factors were analyzed : Question Type, Date of the Month and Temporal Landmark. Levels in the first factor correspond to the three questions asked. For the Date of the Month factor, the fifteen even days analyzed were reduced to 3 categories of 5 days each, so that three levels were defined : "Beginning", "Middle" and "End" of the Month. The Temporal Landmark factor corresponds to the justification of the response. First, we will discuss the Temporal Landmarks. Then we will analyze the results as a function of all three factors.

\subsection{Temporal Landmarks}

In order to justify their response to the test question, $92 \%$ of the subjects referred to landmarks (events or dates). These were classified as past, current or future. Past Landmarks refer to previous months, Current Landmarks to the current month and Future Landmarks to the following months. Current Landmarks were the most frequent (60.5\%), followed by Past Landmarks (19.4\%) then by Future Landmarks (12.1\%).

For Past and Future Landmarks, we defined a measure for distance from the present, i.e. the deviation between the current month and the month the subject refers to. For example, if the question "What month is it ?" is answered correctly by a subject: "This is March because next month I will be on holiday", then the distance from the present is equal to +1 . Generally the distance from the present was small. The range was $[-2,+5]$, and distances equal to + or -1 represented $86,8 \%$ of the cases. 
The frequency of landmarks as a function of Question Type and Date of the Month is shown in figure 1. From this figure, it can be inferred that the frequency of Future Landmarks increases from the beginning to the end of the month and from the PsM to the FtM question.

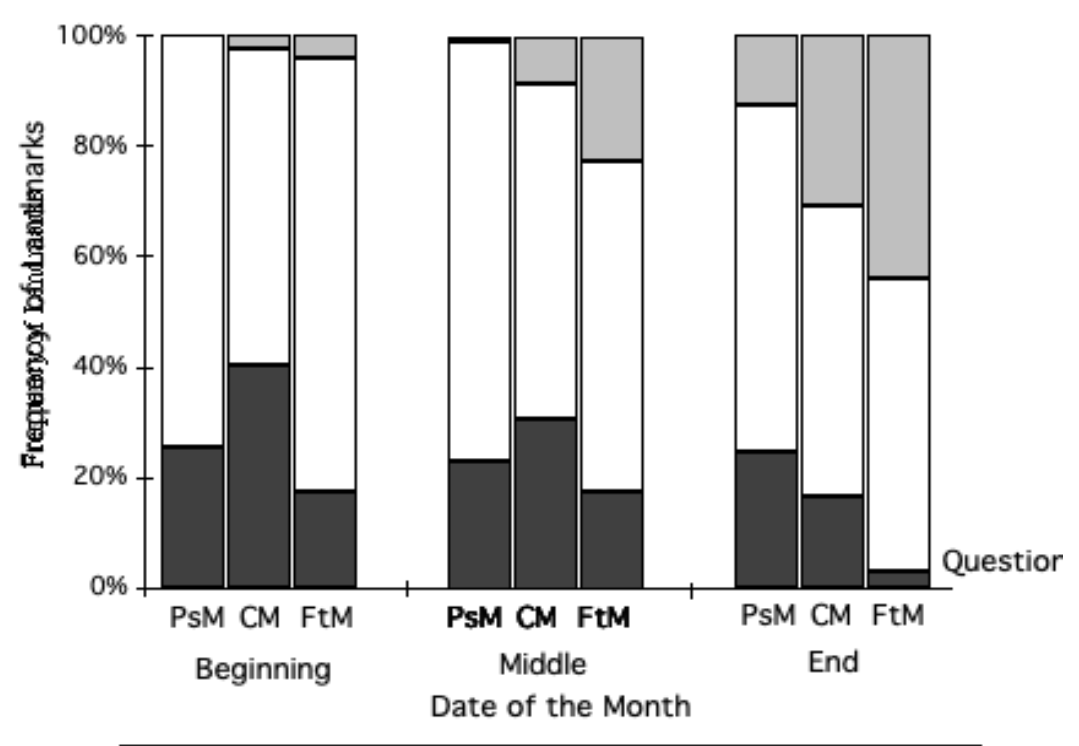

$\square$ Past Landmarks $\square$ Current Landmarks $\square$ Future Landmarks

Figure 1. Frequency of Landmarks as a function of Date of the Month and Question Type.

The relationships between Question type and Date of the Month with Past Landmarks are less clear-cut. Globally speaking, the frequency of Past Landmarks decreases from the beginning to the end of the month. This evolution, however, depends upon the questions asked. For the PsM question, the frequency remains constant throughout the month. For the CM question, it decreases steadily from the beginning to the end of the month. For the FtM question, the frequency of Past Landmarks decreases at the end of the month. It can be noted that, at the end of the month, the FtM question favors the appearance of Future Landmarks, but it is the PsM question that most favors the appearance of Past Landmarks.

Current Landmarks clearly form the majority and they seem to be independent of the Date of the Month and the Question Type.

\subsection{Performance Analysis}


What month is it? / M.F. Valax et al.

Error rate.

The error rate was 5,6\%, and this was about the same for all Question Types.

Table 1: Number of error types related to Temporal Landmarks and Date of the Month

\begin{tabular}{|c|c|c|c|c|c|}
\hline \multirow[b]{2}{*}{ Landmarks } & \multirow[b]{2}{*}{ Error type* } & \multicolumn{3}{|c|}{ Date of the Month } & \multirow[b]{2}{*}{ Total } \\
\hline & & Beginning & Middle & End & \\
\hline \multirow[t]{2}{*}{ Past } & Negative & 12 & 3 & 0 & 15 \\
\hline & Positive & 0 & 0 & 0 & 0 \\
\hline \multirow[t]{2}{*}{ Current } & Negative & 6 & 1 & 1 & 8 \\
\hline & Positive & 0 & 1 & 2 & 3 \\
\hline \multirow[t]{2}{*}{ Future } & Negative & 1 & 0 & 0 & 1 \\
\hline & Positive & 1 & 1 & 12 & 14 \\
\hline \multirow[t]{2}{*}{ Others } & Negative & 8 & 1 & 0 & 9 \\
\hline & Positive & 0 & 2 & 3 & 5 \\
\hline \multirow[t]{3}{*}{ Total } & Negative & 27 & 5 & 1 & 33 \\
\hline & Positive & 1 & 4 & 17 & 22 \\
\hline & Total & 28 & 9 & 18 & 55 \\
\hline
\end{tabular}

The number of errors depends on the interaction between the Date of the Month and the type of Temporal Landmarks used $\left(\chi^{2}[6]=23.8, \mathrm{p}<0.0006\right)$. Table 1 shows that errors are frequent when subjects use Past Landmarks at the beginning of the month and when they use Future Landmarks at the end of the month. In the first case, errors are negative (responses deviated towards the previous months), and in the second case, errors are positive (responses deviated towards the following months). Relatively few errors occur in the middle of the month.

Response Times (RT)

All the correct Response Times were analyzed in a 3X3 ANOVA with Question Type and Date of the Month as between subject variables. There was no main effect of Date of the Month $(\underline{\mathrm{F}}[2,913]=2.5 \underline{\mathrm{p}}<\underline{\mathrm{NS}})$. Question Type, however, showed a highly 
significant effect $(\underline{F}[2,913]=40, \underline{p}<0.0001)$. This effect is modulated by Date of the Month as is clear from the interaction between these factors $(\underline{F}[4,913]=14, \underline{p}<0.0001)$. Figure 2 shows that the CM question is associated with the shortest global mean RT which is stable from the beginning to the end of the month. The mean RTs of the FtM question decrease, and the mean RTs of the PsM question increase from the beginning of the month towards the end. Subjects responded faster at the beginning of the month to the PsM question than to the FtM question $((\underline{F}[1]=3.3, \underline{p}<0.007)$. Conversely, at the end of the month, subjects responded faster to the FtM question than to the PsM question ( $\underline{F}[1]=57.1, \underline{p}<0.0001)$.

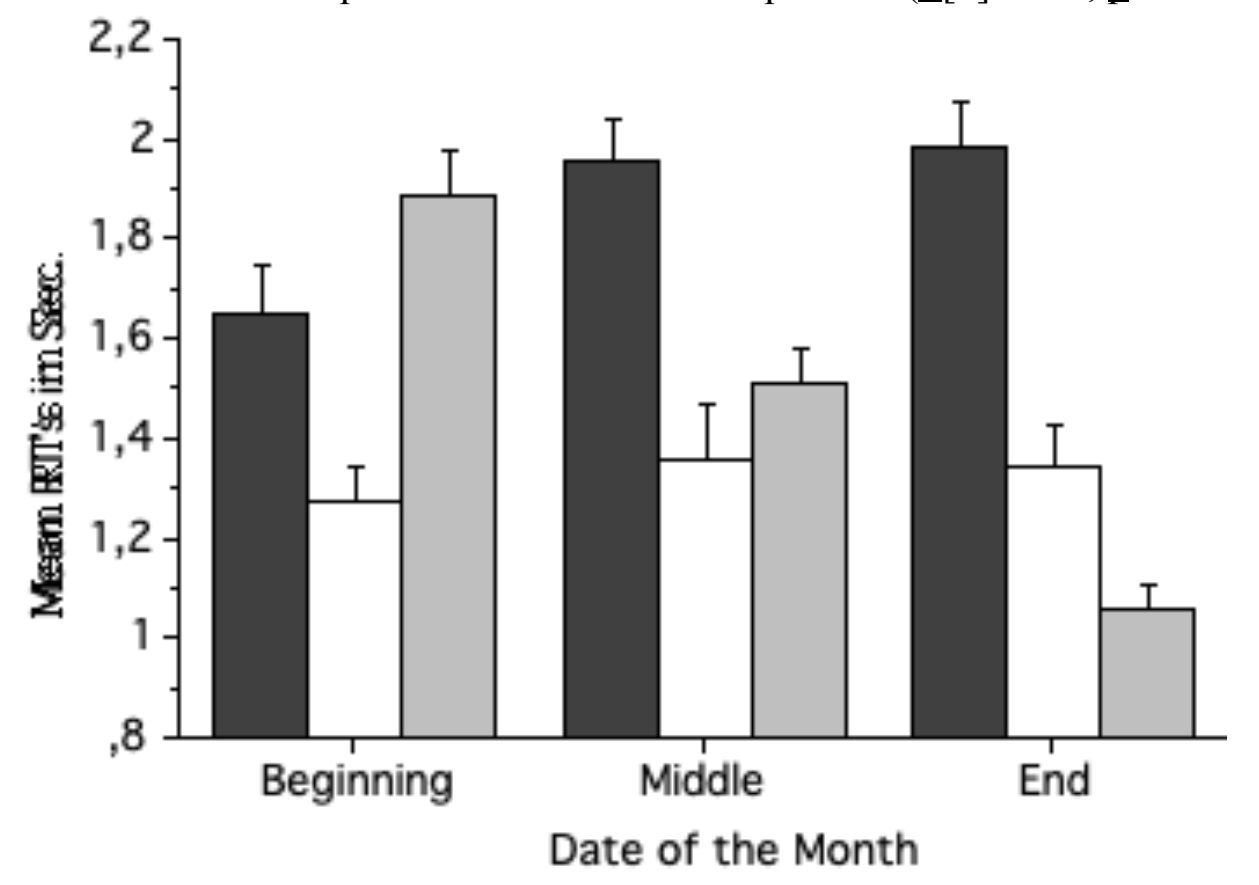

- PsM question $\square \mathrm{CM}$ question $\square \mathrm{FtM}$ question

Figure 2. Variation of Mean RT's as a function of Date of the Month and Question Type.

RT's associated with different types of Temporal Landmarks given (Past, Current, Future) were also determined. The mean RT associated with Past Landmarks is the longest (mean=1.8, $\mathrm{SD}=0.9$ ), followed by the mean RTs associated with Current Landmarks (mean $=1.53, \mathrm{SD}=0.9)$. The shortest is associated with Future Landmarks (mean=1.36, $\mathrm{SD}=0.7)$. These means all differ significantly $(\underline{\mathrm{F}}[2,821]=5.2, \underline{\mathrm{p}}<0.006)$. 


\section{Discussion}

The findings will be discussed from two points of view presented in the introduction section. On the one hand, we will show that, for the "month of the year" time scale unit studied, most of the obtained findings seem to be in line with a spreading activation process. On the other hand, we will use the analysis of the effect of Temporal Landmarks on performance to look at how this process can assimilate results hitherto explained by a matching process.

Previous studies on temporal orientation refer to two distinct processes : the matching process and the spreading activation one. The matching process presupposes comparing a representation of a "temporal script" (e.g., Huttenlocher et al., 1992) with information about the present time. In the unit of time studied here, this process should be expressed by a faster and more accurate identification of the current month in the middle or at the end of the month than at the beginning of the month, and by a homogeneous distribution of errors over the preceding and following months. According to a spreading activation process, activation is spread through a network made up of cognitive units that determine the building of a dynamic and evolving representation. It should be expressed, not through the relationship between the time of the month and performance, but through the effect of contextualized thinking on the activation state of the target representation.

Predictions derived from the matching model are not confirmed. The speed at which the Current Month is identified remains constant throughout the month with response accuracy increasing in the middle of the month and decreasing again at the end of the month. Moreover, at the beginning of the month, wrong responses refer to previous months whereas at the end of the month they refer to following months. However, although our findings do not support a matching process, the script for the months of the year, or at least the juncture between December and January probably plays a part in the process. The transfer of wrong responses to the Previous Months question does not go beyond January. Moreover, the furthest landmark in the past is the "December $31 \mathrm{st}$ ", which is quoted by one subject alone. Thus, on the "month of the year" scale, the juncture 
between December 31st and January 1st seems to act as a "boundary" (Huttenlocher et al, 1992), in the same way as the weekend does on the "days of the week" scale.

As far as the spreading activation process is concerned, our findings globally agree with those obtained for the day of the week. Generally, the Current Month is identified faster than Previous and Future Months. At the beginning of the month, the Previous Month is identified faster than the Future Month and, conversely, at the end of the month, the Future month is identified faster than the Previous Month. Also the use of Temporal Landmarks justifying the response confirms the validity of this process. The Temporal Landmarks were studied as indicators of the events guiding the spreading activation process. This choice seems justified by the correspondence between Temporal Landmarks and the type of errors made. All subjects making a negative error (transferring the response to a previous month) cited a Past Landmark, and almost all the subjects who made a positive error (transferring the response to a future month) cited a Future Landmark. Additionally, the results suggest that the activation of representations adapts to elapsing time and to the problem posed. A majority of subjects used Current Landmarks, whatever the Date of the Month or Question Type. Moreover, the use of Future Landmarks increases towards the end of the month, and from the Previous Month question to the Future Month question. This increase is counterbalanced by a concomitant decrease in the use of Past Landmarks.

The findings discussed so far suggest that temporal orientation is updated continuously in elapsing time. Experiences in time offer the subject memorized or anticipated landmarks that govern a dynamically evolving cognitive structure on which temporal responses are based. From such a process it may be inferred that the availability of temporal landmarks would make it easier to identify a response. In other words, the speed at which the Current Month is identified, at any time of the month, may be linked to the constant availability of Current Landmarks stored in the memory. In the same way, at the beginning of the month, the Previous Month may be identified faster than the Future Month because, at that time, Past Landmarks are more readily available. Conversely, at the 
end of the month, the Future Month is identified faster than the Previous Month because Future Landmarks are more readily available at that time. Although the role of this compatibility is not to be dismissed, the results suggest that the actual situation is more complex.

The compatibility between Temporal Landmarks and responses is confirmed for Future Landmarks. The closer one gets to the Future Month and the more the question focuses on the future, the more these Future Landmarks are used. Moreover, Future Landmarks are associated with faster responses. For Current, and especially for Past Landmarks, this compatibility is less clear. In identifying the Previous Month, Past Landmarks are used with the same frequency throughout the month, and subjects using a Past Landmark respond less quickly than the others. For these subjects, the speed of identification remains constant whatever the Date of the Month and Question Type.

We suggest that the most likely explanation of these results is that use of Past, Current or Future Landmarks does not have the same significance for the experience of time, and that subjects differ in their use of particular types of landmarks. Professional, social or even individual activities will require time to be marked out to a greater or lesser extent. A person who is subjected to considerable temporal constraints (appointments, deadlines, etc.) has a great many events located in the past, present and future, the most important of which, from the point of view of adapting to constraints, are in the future. Conversely, for a person who is more free to manage his time, his/her activity will provide fewer events located in time, and these events will mainly concern what he has just done or experienced or what he is doing or experiencing at the moment. Because there is no obligation to adapt to time constraints, future landmarks are relatively less important. An individual would thus appear to have a sense of location in time that is more accurate the more the individual is subject to future time constraints.

\section{References}

Anderson, J.R., 1983. A spreading activation theory of memory, Journal of Verbal Learning and Verbal Behavior, 22, 261-295. 
Boudes, N. and Tremblay, E., 1994. Temporal Landmarks in dynamic situations, Second International Workshop Interuniversity Pole of Attraction on "Temporal reasoning and behavioral variability: Time and the dynamic control of behavior", Liège, Belgium, November 1994.

Friedman, W.J., 1990. About time: Inventing the fourth dimension. MIT Press.

Friedman, W.J., 1993. Memory of past events. Psychological Bulletin, 113, 1, 44-66.

Huttenlocher, J., Hedges, L.V. and Prohaska, V., 1992. Memory for day of the week: A 5+2 day cycle, J.E.P.: General, 121, 3, 313-325.

Koriat, A. and Fischhoff, B., 1974. What day is today? An inquiry into the process of temporal orientation. Memory and Cognition. 2, 2, 201-205.

Koriat, A., Fischhoff, B. and Razel, O., 1976. An inquiry into the process of temporal orientation. Acta Psychologica. 40, 57-73.

Leplat, J., 1985. Les représentations fonctionnelles dans le travail [Functional representation in work], Revue de Psychologie Française, 30, 269-275.

Lieury A., Aiello, B. Lepreux, D. and Mellet, M., 1980, Le rôle des repères dans la récupération et la datation des souvenirs [The rôle of landmarks in the recovery and dating of memories], L'Année Psychologique, 80, 149-167.

Rumelhart, D.E., Hinton, G., Williams, R. 1986. Learning internal representations by back propagation, in D. E. Rumelhart and J. McClelland and the PDP Research Group, Parallel distributed processing. Explorations in the microstructure of cognition, vol.1, Cambridge, MA, MIT Press.

Shanon, B., 1979. Yesterday, Today and Tomorrow. Acta Psychologica. 43, 469-476.

Valax, M.-F. and Cellier, J-M., 1992. Aides à l'organisation du travail dans les ateliers : problèmes du décalage entre prévision et réalisation. [Work organization aids in the workshops : Problem of Mismatch between planning and execution] In G. de Terssac et P., Dubois (eds) Les nouvelles rationalisations de la production (pp. 121137) Toulouse: Cépaduès.

Weill-Fassina, A., Rabardel and P, Dubois, D., 1993. Représentation pour l'action [Representation for action], Toulouse, Editions Octares. 